\title{
Intravitreal conbercept for choroidal neovascularisation secondary to pathological myopia in a real-world setting in China
}

\section{Intravitreal conbercept was safe and effective in treating myopic choroidal neovascularization}

Xin Nie, Yulong Wang, Hong Yi and Yanbin Qiao*

\begin{abstract}
Background: To evaluate the 12-month efficacy and safety of intravitreal conbercept for myopic choroidal neovascularization (CNV).

Methods: A retrospective, observational study. Thirty-four eyes of 34 pathologic myopic patients with CNV were treated with intravitreal conbercept (IVC) $0.5 \mathrm{mg}$ with a follow up of 12 months. After the first injection, administration of conbercept followed a pro re nata (PRN) regimen. Outcomes included best corrected visual acuity (BCVA), central retinal thickness (CRT), CNV size, the total number of treatments, and adverse events.

Results: The mean patient age was $55.88 \pm 16.17$ years, and the mean eye spherical equivalent was $-8.72 \pm 3.75 \mathrm{D}$. The mean number of IVC over 12 months was $2.12 \pm 0.69$. Overall, best-corrected visual acuity(BCVA)improved from $0.86 \pm 0.33 \log$ MAR at baseline to $0.44 \pm 0.32 \log M A R$ at month $12(p<0.001)$, mean improvement of vision was $4.12 \pm 2.69$ lines. Mean central retinal thickness reduced from $285.9 \pm 104.6 \mu \mathrm{m}$ at baseline to $192.1 \pm 97.5 \mu \mathrm{m}$ at month $12(p<0.001)$. Mean CNV size decreased from $0.52 \pm 0.38 \mathrm{~mm}^{2}$ at baseline to $0.31 \pm 0.19 \mathrm{~mm}^{2}$ at 12 months $(p<0.05)$. All the 34 eyes had reduced or stable size of CNV. Thirty-two eyes $(94.12 \%)$ showed the absence of CNV leakage at the end of the study period. No severe systemic or ocular adverse events were observed.
\end{abstract}

Conclusions: Intravitreal conbercept $0.5 \mathrm{mg}$ was safe and effective for treatment of myopic CNV over 12 months in a real-world setting.

Keywords: Pathologic myopia, Choroidal neovascularization, Anti-VEGF therapy, Conbercept

\footnotetext{
*Correspondence: ybqiao530@163.com

Department of Ophthalmology, Chongqing General Hospital, University of Chinese Academy of Sciences, Pipashan 104, Yuzhong Qu, 400014

Chongqing, P.R. China
}

(c) The Author(s). 2021 Open Access This article is licensed under a Creative Commons Attribution 4.0 International License, which permits use, sharing, adaptation, distribution and reproduction in any medium or format, as long as you give appropriate credit to the original author(s) and the source, provide a link to the Creative Commons licence, and indicate if changes were made. The images or other third party material in this article are included in the article's Creative Commons licence, unless indicated otherwise in a credit line to the material. If material is not included in the article's Creative Commons licence and your intended use is not permitted by statutory regulation or exceeds the permitted use, you will need to obtain permission directly from the copyright holder. To view a copy of this licence, visit http://creativecommons.org/licenses/by/4.0/. The Creative Commons Public Domain Dedication waiver (http://creativecommons.org/publicdomain/zero/1.0/) applies to the data made available in this article, unless otherwise stated in a credit line to the data. 


\section{Background}

Myopic choroidal neovascularization (CNV) is a common cause of vision impairment in young and middle-aged patients with pathologic myopia (PM) in China $[1,2]$. It has been reported that approximately 5 to $11 \%$ of patients with PM will develop myopic CNV [1-3]. Previously, the standard treatment option for myopic CNV was photodynamic therapy (PDT). However, the patients treated with PDT have limited long-term visual outcomes [4]. Recently, anti-vascular endothelial growth factor (anti-VEGF) drugs such as ranibizumab, [5, 6] bevacizumab, [7] and aflibercept [8] have been used to treat myopic CNV with promising results. A study of PDT versus intravitreal bevacizumab (IVB) provided evidence for the superiority of IVB over PDT in treating myopic CNV [9]. The RADIANCE study demonstrated that intravitreal ranibizumab (IVR) provided significant visual improvement over PDT in patients with myopic CNV [5]. In the MYRROR trial, intravitreal aflibercept (IVA) was shown to be safe and effective in treating myopic CNV [8]. Anti-VEGF agents are now considered as first-line therapy for subfoveal and juxtafoveal myopic CNV [10, 11].

Similar to aflibercept, conbercept is an engineered protein that contains the extracellular domain-2 of the VEGF receptor 1 (VEGFR-1), and extracellular domains3 and -4 of the VEGFR-2. The structural difference between conbercept and aflibercept is that conbercept also contains the fourth binding domain of VEGFR-2, which is essential for receptor dimerization and enhances the association rate of VEGF to the receptor $[12,13]$. Although only a few studies employing conbercept to treat myopic $\mathrm{CNV}$ have been reported, the effect of conbercept in patients with neovascular agerelated macular degeneration (nAMD), polypoidal choroidal vasculopathy (PCV), macular edema after retinal vein occlusion (RVO) and diabetic macular edema (DME) are promising [14-17]. Conbercept was approved to treat myopic CNV by the State Food and Drug Administration of China in May 2017. However, there have been very few patients treated with intravitreal conbercept for myopic CNV. This retrospective study aimed to evaluate the 12-month outcomes of Chinese patients with myopic CNV treated with conbercept in a real-world setting.

\section{Methods}

\section{Patients}

This study was approved by the medical ethics committees of Chongqing General Hospital, and was performed in compliance with the 1964 Declaration of Helsinki. We retrospectively reviewed the medical records of 34 eyes from 34 patients with myopic CNV who were treated with intravitreal conbercept (IVC) with a follow-up of 12 months between August 2017 and March 2019.

At baseline and during all subsequent visits, every patient underwent a complete ophthalmic examination, which included best-corrected visual acuity (BCVA), tonometry, biomicroscopy, dilated fundus examination, and OCT (Cirrus; Zeiss, Germany). Fluorescein angiography (FA) was performed before the IVC, and also at 1, 2, 3, and 12 months after the IVC. Furthermore, FA was conducted to confirm the presence of fluorescein leakage in the macular area. The size of CNV was measured in the early-phase FA images using AutoCAD 2007 software in the fundus camera (F-10; NIDEK, Japan).

Patients were included in the study if they were aged $\geq$ 18 years and had high myopia (spherical equivalent $\leq-$ 6.0 diopters or ocular axial length $\geq 26.5 \mathrm{~mm}$ ). In addition, all patients had to have an active subfoveal or juxtafoveal myopic CNV (as documented by spectraldomain OCT [SD-OCT] and FA) and a BCVA of 20/800 or better at baseline. Patients were excluded if they had any one of the following: (1) history of stroke; (2) CNV was secondary to causes other than pathologic myopia; (3) presence of any other ophthalmic diseases; (4) history of treatment with anti-VEGF drugs; (5) prior laser therapy or other intraocular surgery in the studied eye; or (6) intraocular pressure (IOP) $\geq 25 \mathrm{mmHg}$.

\section{Treatment procedure}

Eligible patients received an intravitreal injection of conbercept of $0.5 \mathrm{mg}$ at baseline. Patients then received more injections, as needed, following a pro-re-nata (PRN) schedule. Patients were examined each month for the first 3 months after the injection, and then every three months during the remainder of the follow-up period. Re-treatment was not performed unless any of the following was present in the studied eye: reduction in BCVA by at least 1 Snellen line; increase of at least $100 \mu \mathrm{m}$ in central retinal thickness (CRT) on OCT; new, recurrent, or persistent subretinal or intraretinal fluid; $\mathrm{CNV}$ leakage on FA; or new macular hemorrhage.

\section{Study outcomes}

The primary objective was to measure changes in BCVA from baseline to month 12 in patients with myopic CNV receiving IVC $0.5 \mathrm{mg}$. Secondary objectives included the following measures: changes in CRT on OCT from baseline to month 12; changes in $\mathrm{CNV}$ lesion size on FA from baseline to month 12; number of conbercept injections needed during the 12-month study period; ocular and systemic adverse events resulting from the injection at every study visit. 


\section{Statistical analysis}

The BCVA was assessed using the Snellen chart at a distance of $6 \mathrm{~m}$ and was converted to logarithm of the minimum angle of resolution (LogMAR) for analysis. A change of 0.1 LogMAR was considered a change of one line. Data were presented as mean values \pm standard deviations (SD). Statistical significances of the differences from baseline to 12 months in BCVA, CNV size, and CRT were determined by Wilcoxon signed-rank test, Fisher's exact test and paired $t$-test. Calculations were performed in SPSS Version 17.0 (SPSS, Chicago, IL, USA). A value of less than 0.05 was regarded as statistically significant.

\section{Results}

\section{Baseline characteristics}

Thirty-four eyes of 34 patients with active subfoveal or juxtafoveal myopic CNV were included and treated with at least 1 intravitreal injection of conbercept in this study. A 12-month follow-up was completed in all patients. The baseline and clinical characteristics of these patients are shown in Table 1. The mean age of the 34 patients was $55.88 \pm 16.17$ years with a range of 19 to 78 years. The average spherical equivalent was $-8.72 \pm 3.75$ $\mathrm{D}$ with a range of -6.50 to $-18.00 \mathrm{D}$; the average axial length was $27.35 \pm 1.23 \mathrm{~mm}$ with a range of $26.50-32.52$ $\mathrm{mm}$. The CNV was found in 18 right eyes $(52.9 \%)$ and in 16 left eyes (47.1\%). All patients with CNV were presented with a predominantly classic lesion in the macular area. The mean BCVA in LogMAR was $0.86 \pm 0.33$,

Table 1 Baseline Patient Demographics and Clinical Characteristics

\begin{tabular}{|c|c|}
\hline Characteristic & Patients, $N=34$ (eyes, $N=34$ ) \\
\hline Mean age (SD), yrs & $55.88(16.17)$ \\
\hline \multicolumn{2}{|l|}{ Sex, n (\%) } \\
\hline Male & $22(64.71)$ \\
\hline Female & $12(35.29)$ \\
\hline \multicolumn{2}{|l|}{ Eye side, n (\%) } \\
\hline Right & $18(52.94)$ \\
\hline Left & $16(47.06)$ \\
\hline Mean BCVA (SD), logMAR & $0.86(0.33)$ \\
\hline Mean CRT (SD), $\mu \mathrm{m}$ & $285.9(104.6)$ \\
\hline Mean CNV size (SD), $\mathrm{mm}^{2}$ & $0.52(0.38)$ \\
\hline Mean IOP (SD), mmHg & $15.26(3.21)$ \\
\hline Mean axial length (SD), mm & $27.35(1.23)$ \\
\hline Mean refraction-sphere (SD), diopters & $-8.72(3.75)$ \\
\hline \multicolumn{2}{|l|}{ CNV location, n (\%) } \\
\hline Subfoveal & $30(88.23)$ \\
\hline Juxtafoveal & $4(11.76)$ \\
\hline
\end{tabular}

the mean CRT at baseline was $285.9 \pm 104.6 \mu \mathrm{m}$, and the mean size of the CNV before IVC was $0.52 \pm 0.38 \mathrm{~mm}^{2}$.

\section{Visual and anatomical outcomes}

The mean BCVA logMAR of all patients improved significantly from $0.86 \pm 0.33$ at baseline to $0.44 \pm 0.32$ at month $12(p<0.001)$. Significant improvements in vision were observed at each follow-up visit compared with baseline values $(p<0.001)$ (Fig. 1). The greatest improvement in BCVA was seen during the first 2 months, and the BCVA remained stable afterwards (Fig. 1). The mean improvement in visual acuity was $4.12 \pm 2.69$ lines with a range of 0 to 9 lines at month 12 . An improvement in BCVA of $\geq 3$ lines was seen in nineteen eyes $(55.9 \%$ ), eight eyes $(23.5 \%)$ improved by $\geq 2$ but $<3$ lines, and three eyes $(8.8 \%)$ improved by $\geq 1$ but $<2$ lines. BCVA was unchanged in four eyes $(11.8 \%)$. None of the treated eyes lost $\geq 1$ line of vision.

The mean CRT decreased significantly from $285.9 \pm$ $104.6 \mu \mathrm{m}$ at baseline to $192.1 \pm 97.5 \mu \mathrm{m}$ at month 12 $(p<0.001)$. Significant improvements in CRT were observed at each follow-up visit compared with baseline values $(p<0.001)$ (Fig. 2). The greatest improvement in CRT was seen during the first 2 months, and the CRT remained stable afterwards (Fig. 2). At month 12, subretinal or intraretinal fluid assessed by OCT disappeared in $32(94.1 \%)$ eyes.

Finally, in terms of the mean CNV size, patients with intravitreal conbercept showed a reduction from $0.52 \pm$ $0.38 \mathrm{~mm}^{2}$ at baseline to $0.31 \pm 0.19 \mathrm{~mm}^{2}$ at month 12 $(p<0.05)$. FA showed a significant reduction of mean CNV size at month $2(p<0.05)$. An absence of CNV angiographic leakage was observed by FA in 32 eyes (94.1\%), while slight leakage persisted in 2 eyes (5.8\%) at month 12. All 34 eyes had reduced or stable size of $\mathrm{CNV}$ at the last visit.

\section{Number of Intravitreal Conbercept injections}

Overall, the mean number of IVC was $2.12 \pm 0.69$ with a range of 1 to 4 in all of the 34 eyes. During the 12 -month follow-up, 4 eyes out of the $34(11.8 \%)$ received one injection, 24 eyes $(67.7 \%)$ received two injections, 4 eyes $(11.8 \%)$ received three injections, and 2 eyes $(5.9 \%)$ received four injections. A total of 28 eyes $(82.4 \%)$ needed one or two additional injections in subsequent months after the first injection because of persistent leakage. Two eyes (5.9\%) had recurrence at month 6 and month 9,respectively, and required a total of four injections. These 2 patients had larger subfoveal myopic CNVs. 


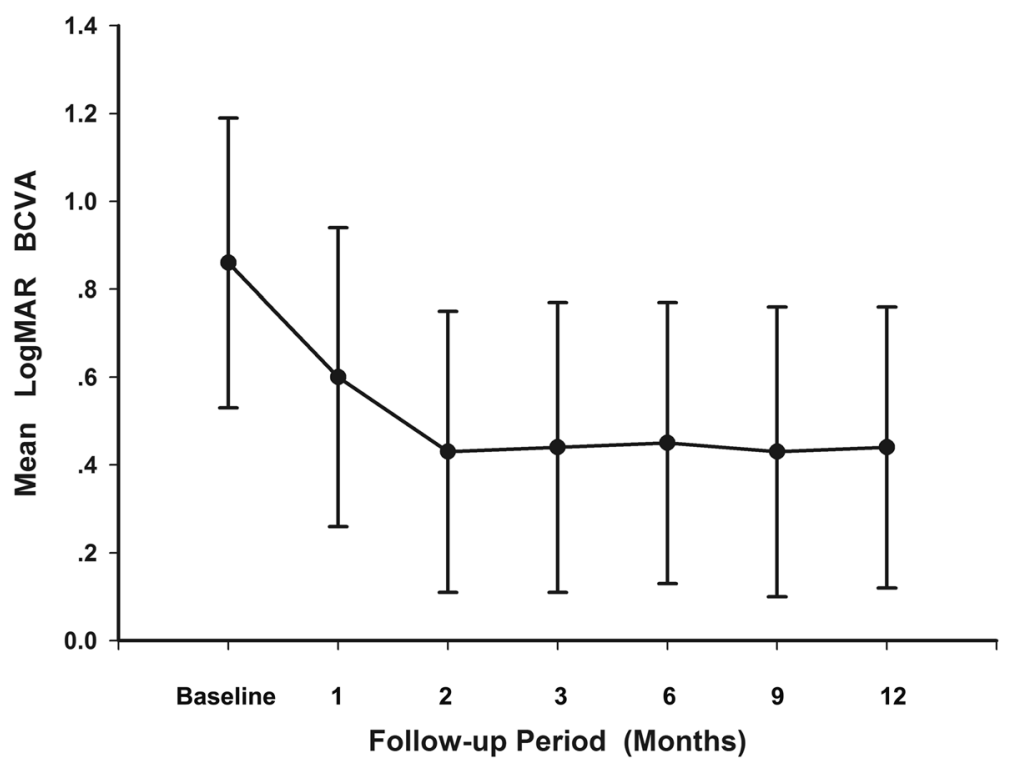

Fig. 1 Mean change in best-corrected visual acuity (BCVA) over 12 months. The significant improvements in vision were observed at each followup visit compared with baseline values $(p<0.001)$. The greatest improvement in BCVA was seen within the first 2 months, and the BCVA remained stable afterwards. Error bar represents standard deviation

\section{Adverse events}

There were no death and no case of cerebrovascular event, endophthalmitis, uveitis, or retinal detachment reported in this study. None of the treated patients demonstrated an IOP elevation during any study visit. The most frequent ocular adverse event was conjunctival hemorrhage, which occurred in 4 eyes $(4 / 34,11.8 \%)$ during the study. Punctate keratitis was reported in 2 eyes $(2 / 34,5.9 \%)$, and eye pain was reported in 3 eyes $(3 / 34,8.8 \%)$.

\section{Discussion}

The current study assessed the efficacy and safety of intravitreal conbercept in a $1+$ PRN regimen as the primary treatment for myopic CNV. Our results showed that intravitreal conbercept provided significant BCVA

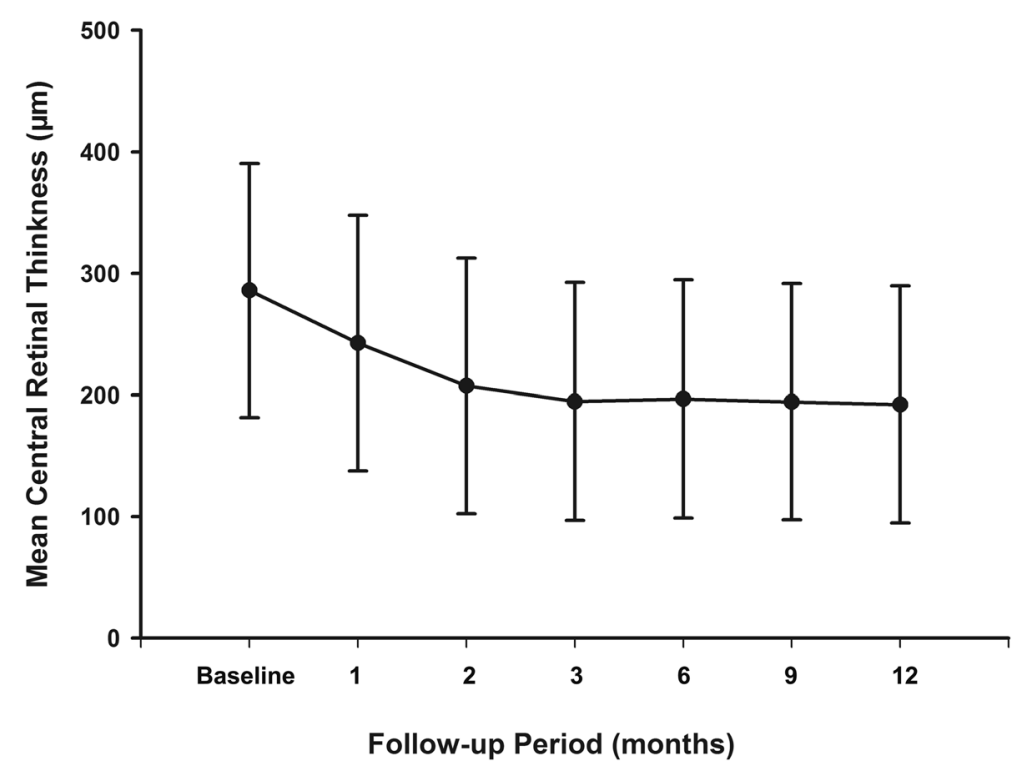

Fig. 2 Mean change in central retinal thickness (CRT) over 12 months. The significant improvements in CMT were observed at each follow-up visit compared with baseline values $(p<0.001)$. The greatest improvement in CRT was seen within the first 2 months, and the CRT remained stable afterwards. Error bar represents standard deviation 
improvement with few injections over 12 months. Treatment with conbercept also showed promising anatomical results. CNV size and CRT decreased significantly in 2 months and then remained stable until the end of the follow-up period. No severe systemic or ocular adverse event was observed. Taken together, these outcomes demonstrated efficacy and safety of conbercept treatment for patients with myopic $\mathrm{CNV}$, in a real-world setting.

In recent years, several studies have demonstrated the promising efficacy of anti-VEGF therapies for the treatment of myopic CNV and have established the use of these agents as first-line therapy for this condition. Ranibizumab was the first anti-VEGF drug approved for the treatment of myopic $\mathrm{CNV}$, having been shown to be more effective than PDT. The efficacy of ranibizumab was confirmed by the RADIANCE study, which demonstrated that BCVA gains were significantly superior with intravitreal ranibizumab than PDT, up to week 12, and that ranibizumab treatment alone was effective in further improving and sustaining BCVA in pathologic myopic patients with CNV over 48 weeks [5]. In the REPAIR study, patients received a single injection of ranibizumab followed by a PRN strategy. There was a mean BCVA improvement of 13.8 letters after 48 weeks with a median of 3 injections [6]. Aflibercept has also been reported to be useful for the treatment of $\mathrm{CNV}$ secondary to PM. The MYRROR study reported a mean BCVA increase of 13.5 letters in aflibercept-treated patients compared with +3.9 letters in sham-treated patients. Patients received a median of 2.6 injections within the first 12 weeks and visual improvement was maintained for up to 48 weeks [8].

Conbercept is a novel anti-VEGF agent with several structural similarities to aflibercept. Conbercept binds VEGF-C, in addition to VEGF-A, VEGF-B, and placenta growth factor (PIGF). Conbercept and aflibercept differ structurally in that conbercept contains a fourth VEGF $\mathrm{R}-2$ binding domain, which is thought to enhance the association rate of VEGF to the receptor and prolong its half-life in the vitreous $[12,13]$. The results of our retrospective study are in general agreement with those noted in the MYRROR trial [8]. In the MYRROR study, patients receiving aflibercept had a mean improvement in BCVA of $2.38 \pm 2.61$ lines at 12 months, achieved with a mean number of $2.12 \pm 0.69$ injections. In addition, the BCVA greatest increase was seen during the first 2 months, and the BCVA remained stable afterwards. In our retrospective study of 34 patients receiving conbercept, the mean improvement was 4.12 lines, with $88 \%$ experiencing visual improvement and $79 \%$ of treated eyes demonstrating an improvement of $\geq 2$ lines, with a mean of 2.12 injections. All 34 eyes demonstrated improved or stable vision for up to 12 months. Treatment with conbercept also improved anatomical results. The mean CRT and CNV size decreased significantly at the end of follow-up period compared with baseline. All 34 eyes had a reduced or stable size of $\mathrm{CNV}$ at the last visit, 32 eyes $(94.12 \%)$ showed a complete closure of CNV on FA. In addition, no serious local or systemic adverse event was noted.

Several reports have supported $3+$ PRN regimen to treat myopic CNV. However, many other trials have demonstrated that $1+\mathrm{PRN}$ is also effective. The results of two different initial dosing schedules of intravitreal ranibizumab for the treatment of $\mathrm{CNV}$ secondary to $\mathrm{PM}$ have been compared, demonstrating that similar visual improvement was attained in both injection strategies [18]. Moreover, $1+\mathrm{PRN}$ regimen received 1.37 fewer injections than $3+$ PRN regimen over 12 months [11]. These results indicated that one single injection followed by PRN might be a reasonable choice for myopic CNV. Our results also demonstrated that a single initial injection of conbercept for myopic $\mathrm{CNV}$ required fewer injections, and provided significant BCVA improvement over 12 months. Four eyes (11.8\%) received one injection, twenty-eight eyes $(82.4 \%)$ needed one to two additional injections after the initial injection, and only 2 eyes $(5.9 \%)$ showed recurrence at 6 and 9 months and needed a total of four injections. Most notably, the greatest improvement in BCVA was seen in the first 2 months in our study, with minimal subsequent reinjections. Regarding the lower number of conbercept injections needed, the most likely explanation is the different features of conbercept compared with other antiVEGF drugs. The lower number of injections needed could also be explained by the reduced aggressiveness of CNV secondary to PM, compared with other causes of $\mathrm{CNV}$. Indeed, myopic CNV is different from other indications for anti-VEGF therapeutics, such as nAMD or DME, for which a proactive treatment is required to achieve sustainable and optimal efficacy. However, even in the case of $\mathrm{CNV}$ due to nAMD, the AURORA trial demonstrated that conbercept sustained visual improvement with fewr injections, within a 12-month follow-up period [16].

Regarding the prognostic factors, several studies pointed out that the total number of injections was significantly associated with age, myopic refraction, CNV size, and CNV location at baseline [19]. The total number of injections may be another indicator of myopic $\mathrm{CNV}$ activity as well as its recurrence. In the current study, focusing mostly on subfoveal CNV $(88.23 \%$ of patients), only four eyes (11.8\%) showed a complete resolution of CNV activity after just one IVC. This resolution rate is markedly lower than the resolution rate of $54.7 \%$ reported by Bruè $C$ et al., [20] who focused on both subfoveal and extrafoveal myopic CNV. In addition, 
in our study, 2 eyes (5.9\%) showed recurrence and needed four injections. These two patients had larger subfoveal CNVs. Thus, our study indicated that subfoveal CNV lesion and larger CNV lesion tended to need a higher number of injections.

The limitations of the current study included its retrospective nature and the relatively small sample size. It also lacked a control group, which is acceptable for a pilot study. Despite these limitations, our results are very promising and support the need for further investigations.

\section{Conclusions}

This retrospective study showed that $1+$ PRN intravitreal conbercept is a safe and effective treatment for myopic $\mathrm{CNV}$, and that the resulting visual improvement can be maintained over 12 months. However, our study was retrospective, had a small sample size, and was conducted in a single ophthalmologic institution. Further multi-center, randomized, long-term, and controlled studies are needed to validate these findings.

\section{Abbreviations \\ BCVA: Best-corrected visual acuity; CNV:: Choroidal neovascularization; CRT: Central retinal thickness; FA: Fluorescein angiography; LogMAR: Logarithm of the minimum angle of resolution; OCT: Optical coherence tomography; PRN: Pro-re-nata; PM: Pathological myopia; VEGF: Vascular endothelial growth factor; IVC: Intravitreal conbercept}

\section{Acknowledgements}

We thank all the patients who participated in this study. The authors would like to express their gratitude to EditSprings () for the expert linguistic services provided.

\section{Authors' contributors}

Design and conduct of the study ( $\mathrm{YQ}$ and $\mathrm{XN}$ ); data collection and management (XN, YW, HY and YQ); analysis and interpretation of data (YQ and $\mathrm{XN}$ ); writing the article (XN); critical revision of the article (YQ). All authors have read and approved the final manuscript.

\section{Funding}

This work was supported by the Chongqing Health and Family Planning Commission (2015HBRC01), and by the Science and Technology Innovation Foundation of Chongqing General Hospital (2016ZDXM01). The funding bodies had no role in the design of the study and collection, analysis, and interpretation of data and in the writing of the manuscript.

\section{Availability of data and materials}

The datasets used and/or analyzed during the current study available from the corresponding author on reasonable request.

\section{Declarations}

\section{Ethics approval and consent to participate}

Approval was obtained by the medical ethics board of Chongqing General Hospital. Written consents were obtained from all the recruited patients.

\section{Consent for publication}

Not applicable.

\section{Competing interests}

None.
Received: 17 February 2020 Accepted: 23 February 2021

Published online: 04 March 2021

\section{References}

1. Neelam K, Cheung CM, Ohno-Matsui K, Lai TY, Wong TY. Choroidal neovascularization in pathological myopia. Prog Retin Eye Res. 2012;31(5): 495-525.

2. Wong TY, Ferreira A, Hughes R, Carter G, Mitchell P. Epidemiology and disease burden of pathologic myopia and myopic choroidal neovascularization: an evidence-based systematic review. Am J Ophthalmol. 2014;157(1):9-25 e12.

3. Ohno-Matsui K, Yoshida T, Futagami S, Yasuzumi K, Shimada N, Kojima A, Tokoro T, Mochizuki M. Patchy atrophy and lacquer cracks predispose to the development of choroidal neovascularisation in pathological myopia. $\mathrm{Br} J$ Ophthalmol. 2003:87(5):570-3.

4. Blinder KJ, Blumenkranz MS, Bressler NM, Bressler SB, Donato G, Lewis $H$, Lim JI, Menchini U, Miller JW, Mones JM, et al: Verteporfin therapy of subfoveal choroidal neovascularization in pathologic myopia: 2-year results of a randomized clinical trial-VIP report no. 3. Ophthalmology 2003, 110(4): 667-673.

5. Wolf S, Balciuniene VJ, Laganovska G, Menchini U, Ohno-Matsui K, Sharma T, Wong TY, Silva R, Pilz S, Gekkieva M. RADIANCE: a randomized controlled study of ranibizumab in patients with choroidal neovascularization secondary to pathologic myopia. Ophthalmology. 2014;121(3):682-92 e682.

6. Tufail A, Narendran N, Patel PJ, Sivaprasad S, Amoaku W, Browning AC, Osoba O, Gale R, George S, Lotery AJ, et al. Ranibizumab in myopic choroidal neovascularization: the 12-month results from the REPAIR study. Ophthalmology. 2013;120(9):1944-5. e1941.

7. Kasahara K, Moriyama M, Morohoshi K, Yoshida T, Simada N, Nagaoka N, Yokoi T, Shinohara K, Kaneko Y, Suga M, et al. SIX-YEAR OUTCOMES OF INTRAVITREAL BEVACIZUMAB FOR CHOROIDAL NEOVASCULARIZATION IN PATIENTS WITH PATHOLOGIC MYOPIA. Retina. 2017;37(6):1055-64.

8. Ikuno Y, Ohno-Matsui K, Wong TY, Korobelnik JF, Vitti R, Li T, Stemper B, Asmus F, Zeitz O, Ishibashi T. Intravitreal Aflibercept Injection in Patients with Myopic Choroidal Neovascularization: The MYRROR Study. Ophthalmology. 2015;122(6):1220-7.

9. Baba T, Kubota-Taniai M, Kitahashi M, Okada K, Mitamura Y, Yamamoto S. Two-year comparison of photodynamic therapy and intravitreal bevacizumab for treatment of myopic choroidal neovascularisation. $\mathrm{Br} \mathrm{J}$ Ophthalmol. 2010;94(7):864-70.

10. Cheung CMG, Arnold JJ, Holz FG, Park KH, Lai TYY, Larsen M, Mitchell P, Ohno-Matsui K, Chen SJ, Wolf S, et al: Myopic Choroidal Neovascularization: Review, Guidance, and Consensus Statement on Management. Ophthalmology 2017

11. Wang $E$, Chen $Y$. Intravitreal anti-vascular endothelial growth factor for choroidal neovascularization secondary to pathologic myopia: systematic review and meta-analysis. Retina. 2013;33(7):1375-92.

12. Wang Q, Li T, Wu Z, Wu Q, Ke X, Luo D, Wang H. Novel VEGF decoy receptor fusion protein conbercept targeting multiple VEGF isoforms provide remarkable anti-angiogenesis effect in vivo. PLoS One. 2013;8(8): e70544.

13. Zhang M, Zhang J, Yan M, Luo D, Zhu W, Kaiser PK, Yu DC. A phase 1 study of KH902, a vascular endothelial growth factor receptor decoy, for exudative age-related macular degeneration. Ophthalmology. 2011;118(4):672-8.

14. Sun Z, Zhou H, Lin B, Jiao X, Luo Y, Zhang F, Tao S, Wu Q, Ke Z, Liu X. EFFl CACY AND SAFETY OF INTRAVITREAL CONBERCEPT INJECTIONS IN MACULAR EDEMA SECONDARY TO RETINAL VEIN OCCLUSION. Retina. 2017; 37(9):1723-30

15. Qu J, Cheng Y, Li X, Yu L, Ke X. EFFICACY OF INTRAVITREAL INJECTION OF CONBERCEPT IN POLYPOIDAL CHOROIDAL VASCULOPATHY: Subgroup Analysis of the Aurora Study. Retina. 2016;36(5):926-37.

16. Li X, Xu G, Wang Y, Xu X, Liu X, Tang S, Zhang F, Zhang J, Tang L, Wu Q, et al. Safety and efficacy of conbercept in neovascular age-related macular degeneration: results from a 12-month randomized phase 2 study: AURORA study. Ophthalmology. 2014;121(9):1740-7.

17. $\mathrm{Xu} Y$, Rong A, Bi Y, Xu W. Intravitreal Conbercept Injection with and without Grid Laser Photocoagulation in the Treatment of Diffuse Diabetic Macular Edema in Real-Life Clinical Practice. J Ophthalmol. 2016;2016:2143082.

18. Kung YH, Wu TT, Huang YH. One-year outcome of two different initial dosing regimens of intravitreal ranibizumab for myopic choroidal neovascularization. Acta Ophthalmol. 2014;92(8):e615-20. 
19. Yang HS, Kim JG, Kim JT, Joe SG. Prognostic factors of eyes with naive subfoveal myopic choroidal neovascularization after intravitreal bevacizumab. Am J Ophthalmol. 2013;156(6):1201-10 e1202.

20. Brue C, Pazzaglia A, Mariotti C, Reibaldi M, Giovannini A. Aflibercept as primary treatment for myopic choroidal neovascularisation: a retrospective study. Eye (Lond). 2016;30(1):139-45.

\section{Publisher's Note}

Springer Nature remains neutral with regard to jurisdictional claims in published maps and institutional affiliations.

Ready to submit your research? Choose BMC and benefit from:

- fast, convenient online submission

- thorough peer review by experienced researchers in your field

- rapid publication on acceptance

- support for research data, including large and complex data types

- gold Open Access which fosters wider collaboration and increased citations

- maximum visibility for your research: over $100 \mathrm{M}$ website views per year

At BMC, research is always in progress.

Learn more biomedcentral.com/submissions 